\title{
TENDÊNCIAS DA PRODUÇÃO CIENTÍFICA DOS BOLSISTAS DE PRODUTIVIDADE EM PESQUISA DO CNPQ DA ÁREA DE EDUCAÇÃO FÍSICA
}

\author{
TRENDS IN SCIENTIFIC PRODUCTION BY PHYSICAL EDUCATION PHD \\ STUDENT RESEARCHERS HOLDING PRODUCTIVITY GRANTS FROM \\ BRAZIL'S NATIONAL COUNCIL OF TECHNOLOGICAL AND SCIENTIFIC \\ DEVELOPMENT (CNPq) C P
}
TENDENCIAS EN LA PRODUCCIÓN CIENTÍFICA DE LOS BECARIOS DE PRODUCTIVIDAD EN INVESTIGACIÓN DEL CNPQ DEL ÁREA DE EDUCACIÓN FÍSICA CP

doi' https://doi.org/10.22456/1982-8918.105434

\author{
Go Tani*<gotani@usp.br> \\ (iD) Ricardo Drews** <ricardo.drews@ufu.br> \\ D Umberto Cesar Corrêa* <umbertoc@usp.br>
}

\footnotetext{
*Universidade de São Paulo. São Paulo, SP, Brasil.

**Universidade Federal de Uberlândia. Uberlândia, MG, Brasil.
}

\begin{abstract}
Resumo: Este estudo buscou analisar a produção científica dos bolsistas de produtividade do Conselho Nacional de Desenvolvimento Científico e Tecnológico $(\mathrm{CNPq})$ da área da Educação Física (PQ-EF), procurando entender a sua trajetória e verificar tendências quanto a publicações de artigos e às eventuais alterações nas suas características no período de 1991 a 2016. Foram analisados os currículos dos 91 bolsistas PQ-EF em curso no ano de 2017, no que diz respeito aos artigos publicados em periódicos, número de coautores e posição na autoria dos artigos, como também a relação entre esses fatores por níveis de bolsa e tempo de término do doutorado. Os resultados revelaram um aumento expressivo da produção científica per capita e também um aumento de publicações multiautorais com número cada vez maior de coautores, sugerindo estratégias de publicação visando ao aumento de produtividade.
\end{abstract}

Palavras chave: Educação Física. Bolsas de estudo. Educação de Pós-Graduação. Indicadores de Produção científica.
Recebido em: 16-07-2020 Aprovado em: 27-10-2020 Publicado em: 29-12-2020

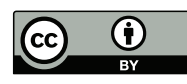

Este é um artigo publicado sob a licença Creative Commons Atribuição 4.0 Internacional (CC BY 4.0). elSSN: 1982-8918 


\section{INTRODUÇÃO}

É de amplo reconhecimento que a instituição da bolsa de produtividade em pesquisa do Conselho Nacional de Desenvolvimento Científico e Tecnológico (CNPq) tem tido efeito significativo no aumento da produção científica brasileira (BARRALNETO; FELÍCIO; CAMARGO, 2007). A sua implementação teve início em 1976, com os objetivos de incentivar a produção científica e contribuir para que o Brasil viesse a alcançar alto grau de consolidação científica (MOTA et al., 2019).

A produção científica dos bolsistas tem despertado interesse de estudo em várias áreas do conhecimento, tais como Saúde Coletiva (BARATA; GOLDBAUM, 2003), Ciências Humanas e Sociais (SILVA; MENEZES; PINHEIRO, 2003), Odontologia (CAVALCANTE et al., 2008; SCARPELLI et al., 2008), Enfermagem (SANTOS et al., 2015), Medicina (MARTINELLI-JUNIOR et al., 2010), Química (SANTOS; CÂNDIDO; KUPPENS, 2010), Nefrologia e Urologia (OLIVEIRA et al., 2011a), Cardiologia (OLIVEIRA et al., 2011b), Medicina Veterinária (SPILKI, 2013), Fonoaudiologia (PELLIZON; CHIARI; GOULART, 2014), Psicologia (SACCO et al., 2016; WEBER et al., 2015) e Educação Física (LEITE et al., 2012; PEDROSO et al., 2017). De modo geral, a bolsa tem cumprido bem a sua finalidade precípua de apoiar pesquisadores já consolidados, que se destacam entre seus pares mediante significativa produção científica na área.

No entanto, é crescente a crítica de que ela estimulou e impulsionou o chamado "produtivismo", que cria um clima de exagerada competição no meio acadêmico, com efeitos prejudiciais tanto pessoais como grupais e institucionais (ANDERSON et al., 2007; SOUSA SANTOS; KIND, 2016). Naturalmente, esse "produtivismo" não começou com a implantação dessa bolsa. Ele é um fenômeno generalizado e disseminado na ciência contemporânea (FANELLI, 2010; GOODSTEIN, 2002; HAGSTROM, 1974; REGO, 2014), em cuja gênese se encontra influência de diferentes fatores, particularmente econômicas e políticas. Já vai longe o tempo em que o conhecimento era fruto apenas de um esforço para saciar a inesgotável curiosidade humana em descrever e explicar fenômenos da natureza. O conhecimento científico se tornou objeto de valor mercadológico altamente rentável atrelado ao desenvolvimento econômico (ANDERSON et al., 2007; TANI, 2014) e instrumento de poder de diferentes naturezas.

Na Educação Física, tudo indica que o efeito danoso mais acentuado tem sido observado no domínio da pós-graduação (TANI, 2016; TANI; CORRÊA, 2019). O esforço exigido para se credenciar e se manter como orientadores no programa, enfrentando pontos de corte cada vez mais elevados de produção, tem sido intenso para todos os pesquisadores, mas o desafio tem sido maior para os orientadores da chamada área sociocultural e pedagógica, em virtude de sua produção científica ser quantitativamente menor em comparação com a dos orientadores da área biológica.

Dois fatos evidenciam o reconhecimento geral no âmbito do sistema brasileiro de pós-graduação em Educação Física sobre a citada diferença na produção científica: (1) o primeiro é que recentemente passou-se a considerar um sistema Qualis de avaliação de livros e capítulos de livro na avaliação de programas, mesmo 
reconhecendo suas limitações em termos de validade; (2) a requalificação das revistas considerando o ISI Social Science Citation Index \& Science and Citation Index na avaliação dos programas no último período quadrienal. Além disso, no entendimento dessa diferença tem sido assinalado que dois aspectos devem ser considerados para uma avaliação mais justa e consistente: a especificidade quanto à dinâmica e ao método de pesquisa e ao tipo de publicação. Os estudos da área sociocultural e pedagógica envolvem, na maioria das vezes, pesquisas qualitativas que requerem análise de dados mais demorada. Ademais, as pesquisas pedagógicas, por serem de natureza aplicada, são mais realizadas no mundo real, que demandam tempo mais extenso para a coleta de dados, comparadas com as pesquisas biológicas realizadas em laboratórios. Relativamente ao tipo de publicações, as produções nessas áreas são mais em forma de livros e capítulos de livro e muitas vezes de autoria simples, contrastando com as publicações de artigos na área biológica que são majoritariamente multiautorais. Mas os orientadores da área sociocultural e pedagógica têm argumentado que essas diferenças não têm sido levadas em devida conta, nem na avaliação da produção científica individual nem da área nos programas de pós-graduação (CORRÊA; CORRÊA; RIGO, 2019; RIGO; RIBEIRO; HALLAL, 2011).

Em termos institucionais, essa diferença tem levado alguns programas de pós-graduação a pensar em se dividir em dois: um para a área biológica e outro para a área sociocultural e pedagógica. Esse tem sido o caso, por exemplo, do programa de pós-graduação a que pertencem dois (o primeiro e o terceiro) dos autores deste texto, um dos mais antigos e conceituados da área, no qual inúmeras vezes ao longo da última década o assunto foi trazido à tona. Assim, pensam que a área biológica poderia competir com mais vigor na busca de melhores conceitos na avaliação da Coordenação de Aperfeiçoamento de Pessoal de Nível Superior (Capes) do Ministério da Educação do Brasil (TANI; CORRÊA, 2019). Implícita nessa avaliação está a aceitação, por parte da instituição, em ter a área pedagógica nos estratos inferiores da avaliação - uma explicitação do até então velado reconhecimento da presença do fenômeno preconceituoso "primo pobre e primo rico" dentro da mesma instituição. Se efetivada, essa divisão certamente teria implicações que vão muito além da pós-graduação, visto que afeta a própria imagem e autoestima da instituição, podendo resultar em cisão institucional interna com reflexos também na graduação e extensão.

Começam a se ouvir vozes de que os efeitos prejudiciais da bolsa de produtividade em pesquisa do CNPq têm atingido um nível insustentável, de maneira que algo necessita ser feito para frear a galopante competição no chamado "produtivismo". No entanto, estudos que façam um diagnóstico baseado em dados concretos para avaliar quais são as mudanças reais que a bolsa tem provocado na Educação Física brasileira ainda não são encontrados na literatura. Evidentemente, a produtividade não depende somente da bolsa, mas os bolsistas de produtividade em pesquisa do CNPq da Educação Física (PQ-EF) constituem um grupo de pesquisadores responsável pela representativa produção científica da área, cuja análise pode fornecer dados importantes para refletir sobre essa demanda de que algo necessita ser feito. 
Diante desse cenário, o objetivo deste artigo é fazer um levantamento e análise da produção científica dos bolsistas PQ-EF em curso no ano de 2017, procurando entender a sua trajetória e verificar tendências quanto a publicações de artigos e as eventuais alterações nas suas características no período de 1991 a 2016 . Essas características se referem a número de artigos, número de coautores por artigo, posição na autoria dos artigos e a relação entre esses fatores por níveis de bolsa e tempo de término do doutorado.

\section{PROCEDIMENTOS METODOLÓGICOS}

Neste estudo retrospectivo e descritivo, foram analisados os currículos dos 91 bolsistas PQ-EF em curso no ano de 2017, no que diz respeito aos artigos publicados em periódicos no período de 1991 até 2016. Para isso, foi obtida a lista de pesquisadores com bolsa de produtividade na área de Educação Física na página eletrônica do CNPq (http://plsql1.cnpq.br/divulg). Em seguida, buscou-se na Plataforma Lattes (http://buscatextual.cnpq.br/buscatextual/busca.do) os currículos dos pesquisadores em questão, sendo a coleta e a extração dos dados realizadas no dia $17 / 11 / 2017$.

Além dos artigos publicados e o nível da bolsa, foram registrados em planilhas do Microsoft Excel o número de autores por artigo e sua respectiva posição de autoria, como também o ano de término do doutorado e a instituição do programa de pós-graduação em que os bolsistas se encontravam credenciados. Os dados foram analisados com base em estatística descritiva dos valores absolutos $(\mathrm{N})$ e relativos (\%) e de tendência central (média).

\section{ANÁLISE DA PRODUÇÃO CIENTÍFICA}

A Tabela 1 mostra os resultados da produção de artigos por níveis de bolsa (níveis $1 \mathrm{~A}, 1 \mathrm{~B}, 1 \mathrm{C}, 1 \mathrm{D}$ e 1E e nível 2) durante o período investigado. É importante ressaltar que, para o recebimento da bolsa de produtividade, o desempenho do pesquisador é avaliado por meio de indicadores referentes ao quinquênio anterior, no caso do nível 2 e do decênio anterior, no caso dos níveis 1D a 1A (CNPq, 2020). Especificamente, os critérios incluem produção científica qualificada, formação de recursos humanos, contribuição para a inovação, coordenação de projetos de pesquisa financiados, participação em atividades de gestão científica e técnicas de relevância inequívoca para a área. A exigência dos critérios é modificada conforme o nível da bolsa, sendo necessário o pesquisador ser contemplado primeiramente com a bolsa nível 2 para posteriormente concorrer a outros níveis de bolsa, de forma gradual.

O número total de artigos publicados foi de 11.317. Chama a atenção o fato de a maior produção ter sido de bolsistas 1B, com a média de 218 artigos no período, seguida de bolsistas 1C com a média de 174,60 artigos. Pesquisadores desses dois níveis tiveram produção média superior do que aqueles que estão no nível $1 \mathrm{~A}$, teoricamente composto de pesquisadores mais produtivos. Por que isso estaria ocorrendo? Uma hipótese explicativa seria porque os bolsistas $1 \mathrm{~A}$, por 
serem normalmente de maior tempo na carreira, poderiam estar desempenhando, comparativamente, outras funções que não as de pesquisa, nomeadamente as administrativas. Entretanto, essa hipótese perde a sustentação quando se observa que a média de produção dos bolsistas 1D é inferior àquela de $1 \mathrm{~B}$ e $1 \mathrm{C}$, aproximandose de 1A (Tabela 1). Esses resultados necessitam, portanto, ser também analisados em relação a mudanças na produção ao longo do período, ou seja, a trajetória de cada bolsista até chegar ao nível de bolsa em que se encontra atualmente, o que será feito mais adiante. Outro fator a ser considerado é a qualidade da produção, avaliada, por exemplo, pelo índice de impacto dos periódicos em que os artigos foram publicados, mas isso não será objeto de análise no presente estudo.

Tabela 1 - Média de artigos publicados pelos bolsistas de produtividade em pesquisa do CNPq da área de Educação Física, por níveis de bolsa, no período de 1991 até 2016.

\begin{tabular}{cccc}
\hline Nível da bolsa & Número de bolsistas & Número de artigos & Média de artigos \\
\hline 1A & 7 & 1108 & 158,2 \\
1B & 5 & 1090 & 218,0 \\
1C & 5 & 873 & 174,6 \\
1D & 19 & 2707 & 142,4 \\
2 & 54 & 5406 & 100,1 \\
SR $^{*}$ & 1 & 133 & 133,0 \\
\hline Total & 91 & 11317 & 124,36 \\
\hline
\end{tabular}

Fonte: Dados da pesquisa.

Legenda: * Bolsista sênior

Outro fator que pode afetar a produtividade é o tempo decorrido a partir da conclusão do doutorado. Como em boa parte das universidades o ingresso na carreira docente demanda o título de doutor, poderia ser inferido que o tempo de término do doutorado teria estreita relação com o tempo de carreira do bolsista. A Tabela 2 apresenta os resultados por níveis de bolsa. Pode ser observado que, nos dez primeiros anos após o doutorado, a produção é menor, visto que todos os bolsistas estão no nível 2, o que era de se esperar. Nos cinco anos seguintes observa-se um aumento acentuado da produção, que é mantida pelos dez anos seguintes, quando começa a declinar, tornando-se difícil manter essa produtividade após 25 anos de conclusão do doutorado. Como mostra a Tabela 2, não existe nenhum bolsista $1 \mathrm{~A}$ após 25 anos de conclusão do doutorado. Esses resultados permitem pensar que o período mais produtivo do pesquisador se situa entre o décimo e o vigésimo ano após a conclusão do doutorado. Talvez seja esse um período em que a infraestrutura para a pesquisa já está pronta (laboratórios, equipamentos), o grupo de estudos devidamente constituído e os primeiros mestres e doutores começam a ser formados, contribuindo para o aumento das publicações. É possível, ainda, que o fato de após os 20 anos de conclusão do doutorado a produção começar a cair estar relacionado à hipótese anteriormente citada sobre o envolvimento dos pesquisadores da Educação Física com atividades outras que não a pesquisa, especialmente a administrativa. 
Tabela 2 - Tempo de término do doutorado dos bolsistas de produtividade em pesquisa do CNPq da área de Educação Física.

\begin{tabular}{cccccccc}
\hline \multirow{2}{*}{ Anos } & Número de bolsistas & \multicolumn{7}{c}{ Níveis de bolsa } \\
\cline { 3 - 7 } & & 1A & 1B & 1C & 1D & $\mathbf{2}$ & SR \\
\hline Até 5 & 3 & - & - & - & - & 3 & - \\
$5-10$ & 22 & - & - & - & - & 22 & - \\
$11-15$ & 25 & 1 & 2 & - & 7 & 15 & - \\
$16-20$ & 22 & 3 & 2 & 4 & 5 & 8 & - \\
$21-25$ & 13 & 3 & - & - & 7 & 3 & - \\
$26-30$ & 2 & - & - & 1 & - & 1 & - \\
$31-$ & 4 & - & 1 & - & - & 2 & 1 \\
\hline Total & 91 & 7 & 5 & 5 & 19 & 54 & 1 \\
\hline
\end{tabular}

Fonte: Dados da pesquisa.

Um fato histórico merece ser considerado na análise dessa questão. Ainserção efetiva da Educação Física na academia deu-se com o início da pós-graduação ocorrida no final da década de 1970 e início da década de 1980 (TANI, 1996). Isto coincidiu com o retorno do exterior de alguns docentes e pesquisadores com os seus doutorados concluídos. Coube a esses docentes fazer a transição de uma Educação Física centrada no curso de preparação profissional para uma Educação Física comprometida também com a produção do seu próprio corpo de conhecimentos.

Isto exigiu desses primeiros docentes e pesquisadores doutores da área um esforço para preparar toda a infraestrutura relacionada com a pesquisa (laboratórios, equipamentos, grupos de pesquisa, eventos e periódicos), o que limitou um envolvimento mais ativo com o desenvolvimento de suas próprias pesquisas. Mais do que isso, tiveram que assumir precocemente as atividades administrativas (TANI, 2000; 2007) como presidência de comissões, chefias de departamento e direção de unidades, visto que os recursos humanos responsáveis por essas funções, até então, estavam em estágios avançados de idade e de carreira e se aposentaram em pouco tempo.

Na realidade, formou-se um gap de formação dentro de uma mesma geração de docentes, ou seja, entre aqueles que foram fazer o doutorado no exterior e aqueles que permaneceram no Brasil sem ter tido a oportunidade de realizar os estudos de pós-graduação. Reconhece-se o esforço e a dedicação desses docentes que permaneceram em assumir cargos administrativos para substituir os que foram fazer o doutorado no exterior. No entanto, como o exercício de muitas funções administrativas na universidade demanda o título de doutor, a responsabilidade recaiu predominantemente sobre o primeiro grupo de docentes após o seu retorno. Obviamente, em relação às funções administrativas em que não se exige o título de doutor para o seu exercício, muitos docentes sem o doutorado continuaram dando a sua importante contribuição, muitas vezes sacrificando o progresso na carreira.

A tendência de envolvimento precoce com atividades administrativas na Educação Física ainda não foi equacionada. Prevalece o efeito cascata, visto que muitos dos atuais ocupantes de cargos administrativos são relativamente jovens, a maioria deles doutores formados por esses docentes que foram os primeiros a ir ao exterior fazer o doutorado. Alguns fizeram apenas o mestrado com eles e posteriormente foram fazer o doutorado no exterior ou em áreas correlatas no Brasil. 
Esses doutores de "segunda geração" têm gerenciado melhor o seu envolvimento precoce com a administração, sem ser afetados na produção científica como foram os da "primeira geração", talvez em virtude de encontrarem uma infraestrutura para a pesquisa já montada. Pode-se pensar também que eles fizeram o doutorado num estágio cientificamente mais avançado da Educação Física como área de conhecimento, o que Ihes proporcionou uma formação mais sólida para a pesquisa.

A produtividade de pesquisa tem, naturalmente, uma relação íntima com a pós-graduação. Muitas publicações dos pesquisadores orientadores são feitas em coautoria com seus orientados. A Tabela 3 mostra o número de bolsistas por níveis de bolsa e o conceito do programa de pós-graduação a que pertence junto à Capes (2017). Nota-se uma tendência de a maioria dos programas mais bem avaliados ter maior número de pesquisadores nos níveis superiores de bolsa.

Tabela 3 - Instituições dos bolsistas de produtividade em pesquisa do CNPq da área de Educação Física por níveis de bolsa e o conceito do Programa de Pós-graduação a que pertencem (Ano base, 2017).

\begin{tabular}{|c|c|c|c|c|c|c|c|c|}
\hline \multirow{2}{*}{ Instituição } & \multirow{2}{*}{ Conceito } & \multicolumn{7}{|c|}{ Níveis da bolsa } \\
\hline & & $1 \mathrm{~A}$ & 1B & $1 \mathrm{C}$ & 1D & 2 & SR & Tota \\
\hline USP/EEFE & 7 & 3 & 2 & 1 & 1 & 5 & & 12 \\
\hline UFRGS & 6 & & & 1 & 3 & 5 & & 9 \\
\hline UFPR & 6 & & & 1 & 2 & 2 & & 5 \\
\hline UFSC & 6 & & & & & 3 & & 3 \\
\hline UNESP/RC & 5 & 1 & & 1 & 3 & 2 & & 7 \\
\hline UFMG & 5 & & & 1 & 2 & 4 & & 7 \\
\hline UFV & 5 & & & & 1 & & & 1 \\
\hline UNICAMP & 4 & 1 & 1 & & & 4 & & 6 \\
\hline UNB & 4 & 1 & & & 1 & 2 & & 4 \\
\hline UCB & 4 & & 1 & & 1 & 2 & & 4 \\
\hline UEL & 4 & & & & 1 & 3 & & 4 \\
\hline UDESC & 4 & & & & & 3 & & 3 \\
\hline UERJ & 4 & & & & & 3 & & 3 \\
\hline UNIFESP & 4 & & & & 1 & 1 & & 2 \\
\hline UFPel & 4 & & 1 & & & & & 1 \\
\hline USJT & 4 & & & & & 1 & & 1 \\
\hline UNOPAR & 4 & & & & & 1 & & 1 \\
\hline UFPB & 4 & & & & & 1 & & 1 \\
\hline UPE & 4 & & & & & 1 & & 1 \\
\hline USP/ EACH & 3 & & & & 1 & 2 & & 3 \\
\hline UFRJ & 3 & & & & 1 & 2 & & 3 \\
\hline USP/EEFERP & 3 & & & & & 2 & & 2 \\
\hline UNICSUL* & - & 1 & & & & & & 1 \\
\hline UFMS* & - & & & & & & 1 & 1 \\
\hline UNESC* & - & & & & 1 & & & 1 \\
\hline USP/FMUSP* & - & & & & & 1 & & 1 \\
\hline UNIPAMPA* & - & & & & & 1 & & 1 \\
\hline UNICID* & - & & & & & 1 & & 1 \\
\hline UNINOVE* & - & & & & & 1 & & 1 \\
\hline UNIVBRASIL* & - & & & & & 1 & & 1 \\
\hline
\end{tabular}

Fonte: Dados da pesquisa.

Legenda: * O relatório de avaliação Capes (2017) da área de Educação Física não apresentou o conceito do programa de pós-graduação dessa instituição 
O acompanhamento das avaliações da pós-graduação nos últimos 30 anos por parte de um dos autores deste texto permite dizer que dificilmente um programa é bem avaliado quando não tem no seu quadro de orientadores bolsistas de nível 1 . Obviamente há exceções que nos remetem a cuidado com as generalizações. Por exemplo, observa-se que a Universidade Federal de Santa Catarina (UFSC), que tem apenas bolsistas de nível 2 e tem conceito 6 na Capes. O inverso é também verdadeiro, com a Universidade Estadual de Campinas (Unicamp), que, apesar de ter bolsistas de nível 1, o seu programa de pós-graduação tem conceito 4. São poucos os bolsistas que não estão envolvidos com a pós-graduação, atestando a forte relação entre a pesquisa e a pós-graduação.

Como tem sido divulgada, a produção científica da Educação Física no que se refere a artigos tem crescido de forma marcante nas últimas décadas (HALLAL; MELO, 2017; KOKUBUN, 2006; VITOR-COSTA; MAIA DA SILVA; SORIANO, 2012). A análise da produção científica dos bolsistas de produtividade em pesquisa evidencia esse crescimento (LEITE et al., 2012; PEDROSO et al., 2017). A Figura 1 mostra o número médio de artigos publicados no período. Os valores correspondem à quantidade média de artigos publicados pelos bolsistas que apresentaram ao menos uma publicação nesse período. A média foi calculada em períodos de cinco anos (quinquênio), sendo o último (2011-2016) de seis anos. Nota-se uma tendência de crescimento gradativo no início do período em análise, mais acentuado a partir do quinquênio 1996-2000 e muito mais acentuado a partir do quinquênio 2001- 2005.

Figura 1 - Número médio de artigos publicados pelos bolsistas de produtividade em pesquisa do CNPq da área de Educação Física no período de 1991 até 2016.

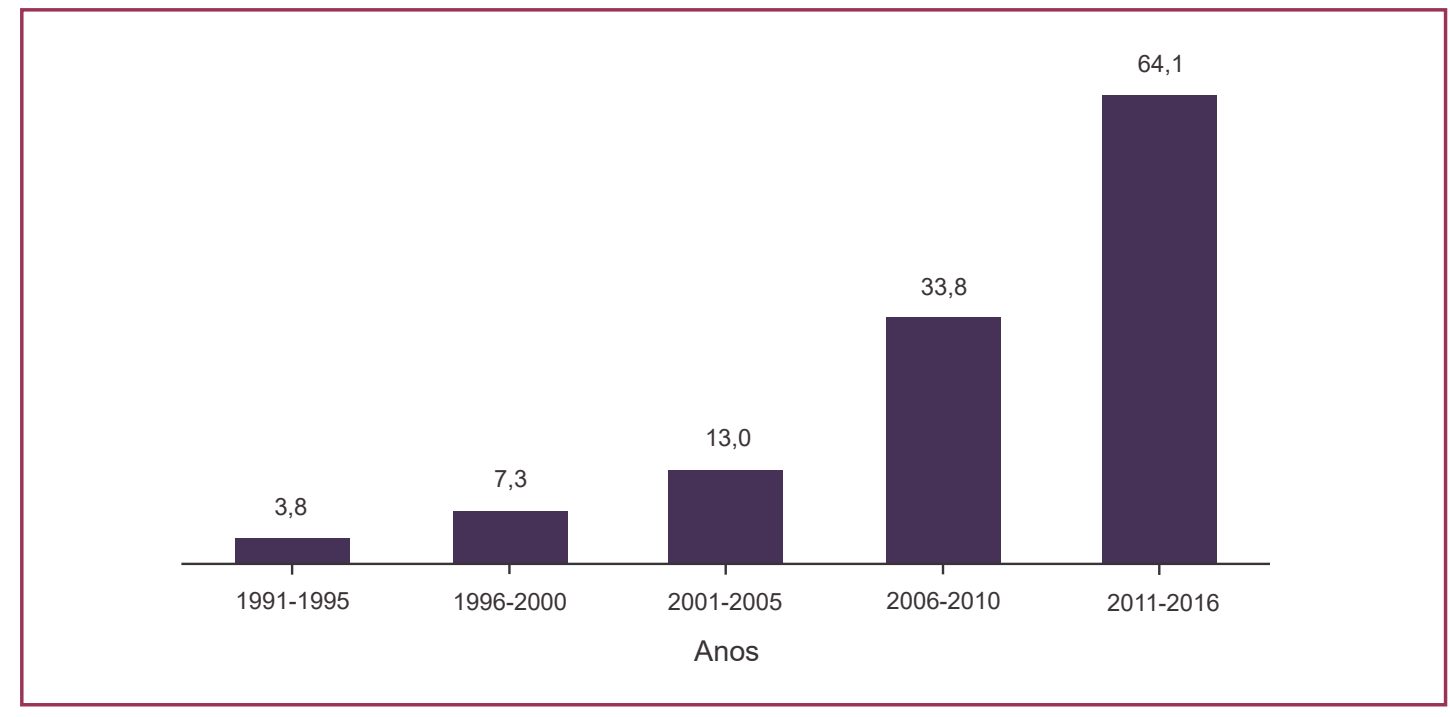

Fonte: Dados da pesquisa.

Pode ser que esse aumento acentuado esteja relacionado com a mudança nos critérios de avaliação dos programas de pós-graduação que aconteceu em 1998, quando a Capes adotou como referência para a avaliação dos programas os padrões internacionais de qualidade e não mais nacionais. Foi instituído um perfil de excelência baseado nesses padrões internacionais, atribuindo-se aos programas que o alcançarem os conceitos 6 e 7, numa escala de 1 a 7 (TANI, 2000). Com essa 
alteração nos critérios de avaliação, a publicação em periódicos internacionais de impacto tornou-se uma meta a ser perseguida por todas as áreas de conhecimento. $\mathrm{E}$ para avaliar qualitativamente a produção científica, foi criado um sistema denominado de Qualis. Mas, segundo Barata (2016), o Qualis Periódicos não deve ser considerado como uma fonte adequada de classificação da qualidade dos periódicos científicos para outros fins que não a avaliação dos programas de pós-graduação.

Muitos atribuem a essa mudança na política de avaliação da Capes o início da "corrida" para a produtividade em pesquisa (TANI, 2007, 2016). Obviamente ninguém pode ser contra a produção do conhecimento. Trata-se de uma das atribuições precípuas de pesquisadores e docentes que estão na carreira universitária. Como é amplamente conhecido, desenvolver as atividades de ensino, pesquisa e extensão são as três funções básicas do docente universitário. Nada tem de errado em ser eficiente nessas atividades, ou seja, produtivo; muito pelo contrário.

Nesse sentido, existe um dado histórico que não é considerado pelos críticos da produtividade que é fundamental para um posicionamento mais sensato e justo a respeito dessa questão: à época em que houve a mudança na política de avaliação da Capes, muitos dos orientadores de pós-graduação em Educação Física não tinham sequer um artigo publicado no biênio em avaliação (1996-1997), de modo que não era nada trivial justificar até mesmo a presença da área no sistema de pós-graduação (KOKUBUM, 2006).

Um dos autores deste artigo era representante de área na Capes nessa época. A Educação Física estava de fato necessitando de uma "chacoalhada" para ser despertada quanto à necessidade de fazer pesquisa e publicar. Portanto, é preciso diferenciar a necessidade de aceleração da produção do conhecimento que a Capes sinalizou, o que foi absolutamente justificado, ainda mais para uma área de conhecimento ainda incipiente em busca de consolidação acadêmico-científica (TANI, 1996), com o "produtivismo" dos dias de hoje.

A Figura 2 mostra o número médio de artigos publicados pelos bolsistas PQEF no período de 1991 até 2016, levando-se em consideração os diferentes níveis da bolsa. Todos os níveis da bolsa aumentaram gradativamente o número de artigos a partir do quinquênio 1996-2000, com aumento expressivo a partir do quinquênio 2001-2005, notadamente os bolsistas 1B. Como foi discutido, os bolsistas 1B são aqueles que provavelmente dispunham de maior tempo para se dedicar à pesquisa, pois estavam mais livres de outras atividades como a administrativa, além de estarem na fase mais produtiva da carreira.

No entanto, esse crescimento da produção merece uma análise mais detalhada para verificar se houve alguma mudança na forma de publicação no que se refere a número de autores por artigo e a posição dos pesquisadores na autoria dos artigos. Isto porque pode ter havido a publicação de artigos com a participação de mais de um bolsista, o que acarretaria a computação de um mesmo artigo na produção de todos eles. 
Figura 2 - Número médio de artigos publicados pelos bolsistas de produtividade em pesquisa do CNPq da área de Educação Física no período de 1991 até 2016 levando-se em consideração os diferentes níveis de bolsa de produtividade

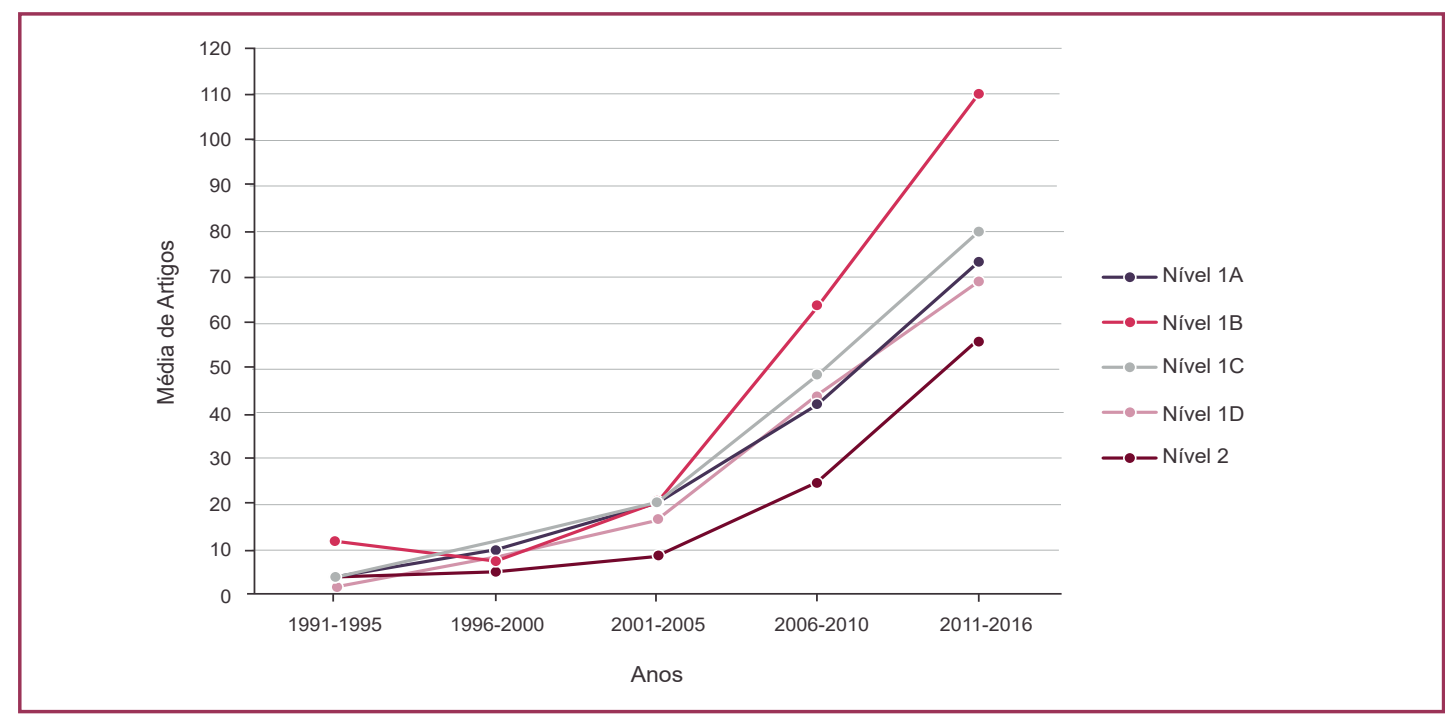

Fonte: Dados da pesquisa.

A Figura 3 mostra o percentual de artigos publicados pelos bolsistas PQ-EF no período de 1991 até 2016, levando-se em consideração a posição de autoria. Os valores correspondem à quantidade média de artigos publicados em que os autores ocuparam diferentes posições na autoria dos artigos. No quinquênio 1991-1995 foi encontrado que, do total das publicações, um pouco mais de $60 \%$ foi como primeiro autor, seguido de quase $20 \%$ como $2^{\circ}$ autor, mas isso foi decaindo ao longo do tempo. No período de 2011-2016, a maior parcela (um pouco mais de $30 \%$ ) correspondeu a sexto autor ou posições acima deste. Por outro lado, cresceu proporcionalmente a posição do bolsista como último autor do artigo. A classificação "último autor" corresponde à quantidade de artigos em que se foi último autor independentemente da posição. Assim, quando um artigo tinha somente um autor, ele foi classificado como primeiro autor e também como último autor.

Figura 3 - Percentual de artigos publicados pelos bolsistas de produtividade em pesquisa do CNPq da área de Educação Física no período de 1991 até 2016 levando-se em consideração a posição de autoria.

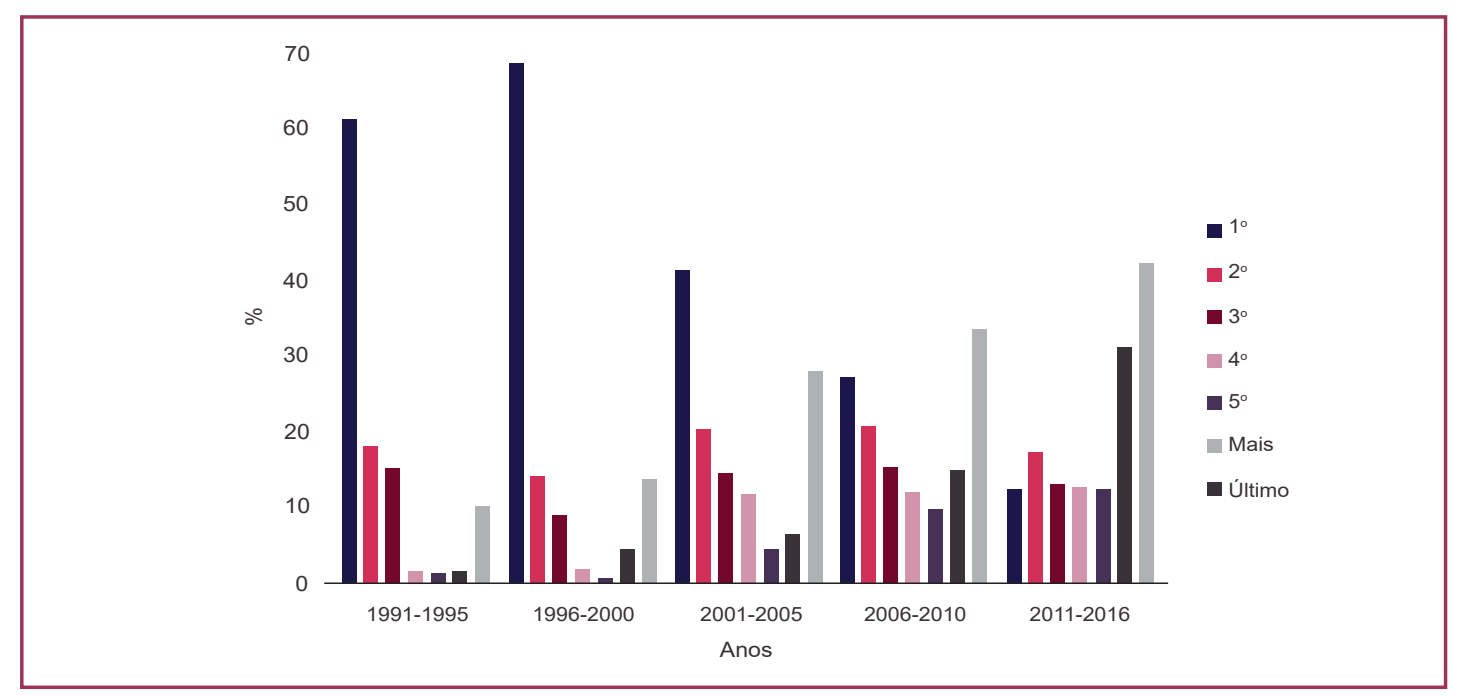

Fonte: Dados da pesquisa.

Legenda: $1^{\circ}$ : primeiro autor; $2^{\circ}$ : segundo autor; $3^{\circ}$ : terceiro autor; $4^{\circ}$ : quarto autor; $5^{\circ}$ : quinto autor; Mais: sexto ou outras colocações acima de seis autores; Último: último autor. 
Esses resultados revelam que existe uma tendência de crescimento do bolsista PQ-EF ser o último autor do artigo, independentemente do número total de coautores. Isto é de se esperar, visto que existe uma cultura nas publicações em que o mentor intelectual do artigo tende a ser o último autor, e o orientador é, via de regra, o mentor dos artigos publicados com os seus orientandos de pós-graduação.

Porém, chama a atenção o aumento marcante de artigos com vários coautores, ou seja, o inchaço no número de autores por artigo. Isto pode ser verificado na Figura 4, em que é apresentado o percentual de autores por artigos publicados dos bolsistas PQ-EF no período de 1991 até 2016. Por exemplo, no quinquênio 1991-1995, foi encontrado que do total das publicações, um pouco mais de $20 \%$ tiveram um, dois ou três autores. Por outro lado, no período de 2011-2016, a maior parcela (um pouco mais de $50 \%$ ) teve seis ou mais autores.

Figura 4 - Percentual de autores por artigos publicados dos bolsistas de produtividade do CNPq da área de Educação Física no período de 1991 até 2016.

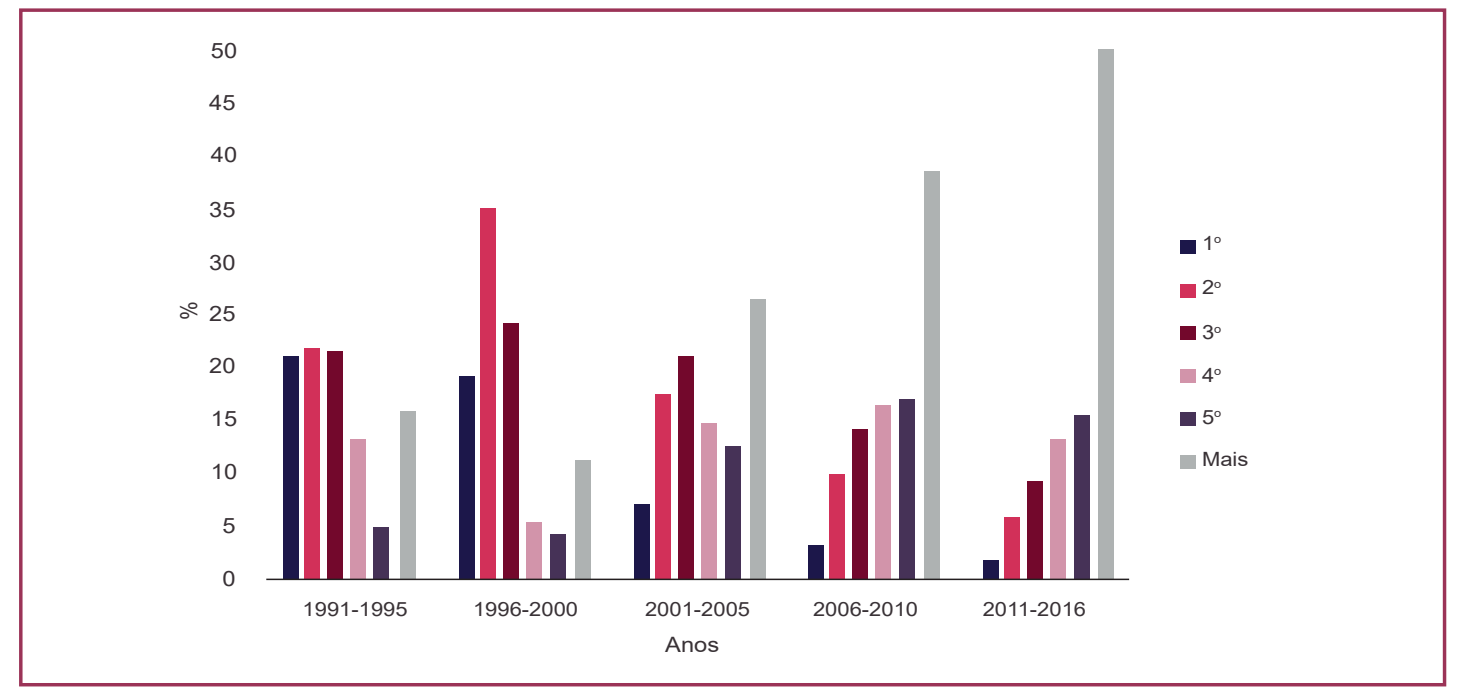

Fonte: Dados da pesquisa

Legenda: 1: um autor; 2: dois autores; 3: três autores; 4: quatro autores; 5: cinco autores; Mais: seis ou mais autores.

Esse aumento proporcional de artigos com número crescente de coautores dos bolsistas PQ-EF poderia ser parcialmente explicado se os estudantes de pósgraduação trabalhassem todos em equipe, um colaborando com o projeto do outro e publicando coletivamente com o orientador, o que nem sempre acontece, visto que cada um tem o seu projeto de tese ou dissertação e prazo para a defesa. Outras explicações plausíveis seriam, por exemplo, o crescimento significativo da sua interação com um grande número de parceiros, o aumento da participação ativa em redes de pesquisa produtivas e o envolvimento efetivo em consórcios de pesquisadores em torno de projetos temáticos de grande porte. Caso isto não tenha acontecido, esse resultado pode sugerir uma estratégia grupal de aumento de publicações.

De todas as maneiras, esses resultados merecem uma análise ainda mais detalhada, mesmo porque é difícil de entender que de repente aumentaram-se pesquisas em grupos, parcerias, consórcios ou redes de pesquisa, a tal ponto de 
explicar esse crescimento acentuado de artigos com número elevado de coautores. A Tabela 4 mostra a relação entre o número médio de artigos publicados pelos bolsistas PQ-EF no período de 1991 a 2016 e a posição de autoria nesses artigos. Percebe-se claramente uma relação inversa entre a média da produção dos bolsistas e o número de artigos como primeiro autor e uma relação de semelhança com o aumento de artigos em que se é o sexto autor ou mais.

Tabela 4 - Percentual de artigos por posição de autoria e sua relação com a média de artigos publicados pelos bolsistas de produtividade do CNPq da área de Educação Física no período de 1991 até 2016.

\begin{tabular}{cccccc}
\hline \multirow{2}{*}{ Posição } & \multicolumn{5}{c}{ Período } \\
\cline { 2 - 6 } & $\mathbf{1 9 9 1 - 1 9 9 5}$ & $\mathbf{1 9 9 6 - 2 0 0 0}$ & $\mathbf{2 0 0 1 - 2 0 0 5}$ & $\mathbf{2 0 0 6 - 2 0 1 0}$ & $\mathbf{2 0 1 1 - 2 0 1 6}$ \\
\hline $1^{\circ}$ & 61,54 & 68,74 & 41,48 & 27,15 & 12,54 \\
$2^{\circ}$ & 18,07 & 14,44 & 20,45 & 20,73 & 17,42 \\
$3^{\circ}$ & 15,33 & 9,18 & 14,75 & 15,42 & 13,23 \\
$4^{\circ}$ & 1,77 & 1,67 & 11,98 & 12,05 & 12,81 \\
$5^{\circ}$ & 1,52 & 0,88 & 4,63 & 9,75 & 12,58 \\
$6^{\circ}$ ou mais colocações & 1,77 & 4,66 & 6,70 & 14,90 & 31,41 \\
Média de artigos & 3,83 & 7,33 & 13,01 & 33,78 & 64,10 \\
publicados & & & & & \\
\hline
\end{tabular}

Fonte: Dados da pesquisa.

Legenda: $1^{\circ}$ : primeiro autor; $2^{\circ}$ : segundo autor; $3^{\circ}$ : terceiro autor; $4^{\circ}$ : quarto autor; $5^{\circ}$ : quinto autor; $6^{\circ}$ : sexto autor.

A Tabela 5 apresenta a relação entre o número médio de artigos publicados pelos bolsistas PQ-EF no período de 1991 até 2016 e o percentual de autores por artigos publicados, sem relação com a posição de autoria. Observa-se uma tendência clara de aumento no número médio de autores por artigo, proporcional ao aumento médio do número de publicações.

Tabela 5 - Percentual de autores por artigo e sua relação com a média de artigos publicados pelos bolsistas de produtividade do CNPq da área de Educação Física no período de 1991 até 2016.

\begin{tabular}{cccccc}
\hline \multirow{2}{*}{$\mathbf{N}^{\circ}$ de autores } & \multicolumn{5}{c}{ Período } \\
\cline { 2 - 5 } & $\mathbf{1 9 9 5 - 1 9 9 1}$ & $\mathbf{1 9 9 6 - 2 0 0 0}$ & $\mathbf{2 0 0 1 - 2 0 0 5}$ & $\mathbf{2 0 0 6 - 2 0 1 0}$ & $\mathbf{2 0 1 1 - 2 0 1 6}$ \\
\hline 1 & 21,32 & 19,29 & 7,29 & 3,21 & 1,87 \\
2 & 21,80 & 35,19 & 17,66 & 10,06 & 5,88 \\
3 & 21,66 & 24,27 & 21,15 & 14,28 & 9,58 \\
4 & 13,38 & 5,60 & 14,66 & 16,61 & 13,32 \\
5 & 5,13 & 4,32 & 12,69 & 17,20 & 15,55 \\
6 ou mais autores & 15,96 & 11,32 & 26,55 & 38,64 & 53,80 \\
Média de artigos & 3,83 & 7,33 & 13,01 & 33,78 & 64,10 \\
publicados & & & &
\end{tabular}

Fonte: Dados da pesquisa

Legenda: 1: um autor; 2: dois autores; 3: três autores; 4: quatro autores; 5: cinco autores; №: número.

A tendência que se evidencia nessas publicações, concernente à diminuição da média de artigos em que se é o primeiro autor e ao aumento da média do número de autores por artigo, sugere uma mudança de estratégia nas publicações dos 
bolsistas PQ-EF, provavelmente para aumentar a produtividade. A mudança aparece de maneira mais clara a partir do quinquênio 2001-2005 e a continuidade da tendência ainda mais evidente se observa nos quinquênios seguintes.

Essa mudança de estratégia na publicação de artigos seria compreensível e justificada se as ações correspondentes às alternativas de explicações anteriormente mencionadas tivessem sido de fato realizadas. Nesse caso, a competição teria sido normal, imparcial e justa. No entanto, se os próprios órgãos de fomento já identificaram essa mudança de estratégia e resolveram considerar, para efeito de avaliação da produção individual do pesquisador, os artigos em que se é o primeiro ou o último autor (CHIARI et al., 2016; CNPq, 2016, 2017, 2020), é forte a suspeita de que está em curso entre os bolsistas PQ-EF um fenômeno que pode ser caracterizado como um aumento da autoria "obesa" e da coautoria "amiga" nas publicações (TANI, 2014). Os eventuais reflexos dessa medida "profilática" que está sendo tomada pelos órgãos de fomento à pesquisa serão provavelmente percebidos nas avaliações individuais (CNPq) e institucionais (Capes) a ser doravante realizadas.

\section{CONSIDERAÇÕES FINAIS}

Os motivos e as motivações que levam um pesquisador a bem produzir são variados. Podem ser, por exemplo, a realização pessoal, a reputação acadêmica, o respeito e prestígio entre os pares, ou até mesmo a vaidade. Mas é inegável o efeito da recompensa de diferentes naturezas que premiam a produtividade. A bolsa de produtividade em pesquisa do CNPq, em forma de recompensa financeira, é seguramente um potente motivador. Muitas vezes, para além da recompensa, a bolsa é vista como selo de qualidade como pesquisador, o que a torna não apenas um fator de motivação, mas também um sonho de conquista. Naturalmente, o selo de qualidade encerra um aspecto pragmático que é abrir as portas das agências de fomento para solicitações de financiamento.

Entretanto, como o número de bolsas é limitado, a competição inevitavelmente se instala entre os pares. Deste modo, para que essa competição não frustre os objetivos precípuos da bolsa de produtividade em pesquisa do CNPq, é preciso zelar para que ela seja salutar e não resulte numa falsa produtividade. Na realidade, essa preocupação nem sequer deveria existir, mas como os resultados deste estudo sugerem que existem indícios de estratégias produtivistas, resta esperar que as medidas tomadas pelos órgãos de fomento à pesquisa sejam bem-sucedidas e constituam um instrumento "pedagógico" para desestimular a competição que pode estar artificialmente sustentando o "produtivismo". Portanto, em relação àquelas vozes de que algo necessita ser feito, a resposta é: pode ser que seja insuficiente, mas já começou a ser feito. Nesse particular, é sempre oportuno lembrar que a ciência tem mecanismos internos próprios para corrigir erros e fazer correções de rota (GOODSTEIN, 2002).

Por fim, se perguntássemos o que a produção dos atuais bolsistas PQEF mostra, revela e eventualmente oculta, a resposta assim seria: mostra de forma inequívoca o aumento da produção científica per capita, o que merece 
ser reverenciado; revela o aumento de publicações multiautorais e com número cada vez maior de coautores que necessitam ser monitorados de perto; e oculta potenciais estratégias produtivistas para ser competitivo que precisam ser inibidas. Evidentemente, o assunto é complexo de maneira que mais estudos necessitam ser realizados, considerando outras variáveis ou análises como, por exemplo, a estatística inferencial.

\section{REFERÊNCIAS}

ANDERSON, Melissa et al. The perverse effects of competition on scientists' work and relationships. Science and Engineering Ethics, v. 13, n. 4, p. 437-461, 2007. Disponível em: https://link.springer.com/article/10.1007/s11948-007-9042-5. Acesso em: 15 jul. 2020.

BARATA, Rita de Cássia Barradas. Dez coisas que você deveria saber sobre o Qualis. Revista Brasileira de Pós-Graduação, v. 13, n. 30, p. 13-40, 2016. Disponível em: http:// ojs.rbpg.capes.gov.br/index.php/rbpg/article/view/947/pdf . Acesso em: 15 jul. 2020.

BARATA, Rita de Cássia Barradas; GOLDBAUM, Moisés. Perfil dos pesquisadores com bolsa de produtividade em pesquisa do CNPq da área de saúde coletiva. Cadernos de Saúde Pública, v. 19, n. 6, p. 1863-1876, 2003. Disponível em: https://www.scielosp.org/ article/csp/2003.v19n6/1863-1876/pt. Acesso em: 15 jul. 2020.

BARRAL-NETO, Manoel; FELÍCIO, José Roberto Drugowich; CAMARGO, Erney Plessmann. O desempenho da C\&T no Brasil: uma análise a partir dos dados do CNPq. Revista USP, n. 73, p. 48-57, 2007. Disponível em: https://www.revistas.usp.br/revusp/ article/view/13588. Acesso em: 15 jul. 2020.

CAPES. Relatório de Avaliação Quadrienal da Educação Física. Brasília, 2017. Disponível em: https://www.gov.br/capes/pt-br/centrais-de-conteudo/20122017-educacaofisica-quadrienal-pdf/view . Acesso em: 15 jul. 2020.

CAVALCANTE, Raika Augusta et al. Perfil dos pesquisadores da área de odontologia no Conselho Nacional de Desenvolvimento Científico e Tecnológico (CNPq). Revista Brasileira de Epidemiologia, v. 11, n. 1, p. 106-113, 2008. Disponível em: https://www.scielo.br/scielo. php?pid=S1415-790X2008000100010\&script=sci abstract\&tlng=pt. Acesso em: 15 jul. 2020.

CHIARI, Brasília Maria et al. Research productivity grants: physical education, physical therapy, speech pathology, and occupational therapy. Brazilian Journal of Physical Therapy, v. 20, n. 1, p. 1-3, 2016. Disponível em: https://www.scielo.br/scielo. php?pid=S1413-35552016000100001\&script=sci_arttext. Acesso em: 15 jul. 2020.

CNPq. Chamada No 12/2016 - Bolsas de Produtividade em Pesquisa - PQ da Educação Física. Brasília. 2016. Disponível em: http://www.cnpq.br/web/guest/chamadaspublicas?p p id=resultadosportlet WAR resultadoscnpqportlet INSTANCE 0ZaM\&id=5881-4140\&detalha=chamadaDetalhada\&filtro=encerradas. Acesso em: 15 jul. 2020

CNPq. Chamada No 12/2017 - Bolsas de Produtividade em Pesquisa - PQ da Educação Física. Brasília, 2017. Disponível em: http://www.cnpq.br/web/guest/chamadaspublicas?p p id=resultadosportlet WAR resultadoscnpqportlet INSTANCE 0ZaM\&id=5884-4788\&detalha=chamadaDetalhada\&filtro=encerradas. Acesso em: 15 jul. 2020. 
CNPq. Chamada No 09/2020 - Bolsas de Produtividade em Pesquisa - PQ da Educação Física. Brasília, 2020. Disponível em: http://www.cnpq.br/web/guest/chamadaspublicas?p p id=resultadosportlet WAR resultadoscnpqportlet INSTANCE 0ZaM\&id=58107-6827\&detalha=chamadaDetalhada\&filtro=abertas. Acesso em: 15 jul. 2020.

CORREAA, Marluce Raquel Decian; CORRÊA, Leandro Quadro; RIGO, Luis Carlos. A pós-graduação na educação física brasileira: condições e possibilidades das subáreas sociocultural e pedagógica. Revista Brasileira de Ciências do Esporte, v. 41, n. 4, p. 359-366, 2019. Disponível em: https://www.scielo.br/scielo.php?pid=S010132892019000400359\&script=sci_arttext. Acesso em: 15 jul. 2020.

FANELLI, Daniele. Do pressures to publish increase scientists' bias? An empirical support from US States Data. PloS one, v. 5, n. 4, e10271, 2010. Disponível em: https://journals. plos.org/plosone/article?id=10.1371/journal. pone.0010271. Acesso em: 15 jul. 2020.

GOODSTEIN, David. Scientific misconduct. Academe, v. 88, n. 1, p. 28-31, 2002.

HAGSTROM, Warren. Competition in science. American Sociological Review, v. 39, n. 1, p. 1-18, 1974. Disponível em: https://www.jstor.org/stable/2094272?casa token=2jxvbB NKWQAAAAA\%3AY-JljIDcKYYkPoQXDO2ut2pgcRLk5ezFyyAPp7BłZHwknQYyy7ZpiViVRUg tfph_WAVMVuKCPpEs66_UrunILOKYJDif_oytdH98DnSD0liQp7G5FFIJgA\&seq=1\#metadata info_tab_contents. Acesso em: 15 jul. 2020.

HALLAL, Pedro Curi; MELO, Victor Andrade de. Crescendo e enfraquecendo: um olhar sobre os rumos da Educação Física no Brasil. Revista Brasileira de Ciências do Esporte, v. 39, n. 3, p. 322-327, 2017. Disponível em: https://www.scielo.br/scielo.php?pid=S010132892017000300322\&script=sci_abstract\&tIng=es. Acesso em: 15 jul. 2020.

KOKUBUN, Eduardo. Pós-graduação em educação física. Revista Brasileira de Educação Física e Esporte, v. 20, n. 5, p. 31-33, 2006. Disponível em: http://citrus.uspnet.usp.br/eef/ uploads/arquivo/9 Anais_p31.pdf. Acesso em: 15 jul. 2020.

LEITE, Bárbara D. Gusmão Lopes et al. Perfil dos pesquisadores com bolsa de produtividade no Conselho Nacional de Desenvolvimento Científico e Tecnológico (CNPq) da área da educação física. Motricidade, v. 8, n. 3, p. 90-98, 2012. Disponível em: http:// www.scielo.mec.pt/scielo.php?script=sci arttext\&pid $=$ S1646-107X2012000300010. Acesso em: 15 jul. 2020.

MARTELLI-JUNIOR, Hercílio et al. Pesquisadores do CNPq na área de medicina: comparação das áreas de atuação. Revista da Associação Médica Brasileira, v. 56, n. 1, p. 478-483, 2010. Disponível em: https://www.scielo.br/scielo.php?pid=S010442302010000400024\&script=sci_arttext\&tlng=pt. Acesso em: 15 jul. 2020.

MOTA, Ana Cláudia de Souza et al. A evolução dos bolsistas de produtividade e de desenvolvimento tecnológico do CNPq: um estudo de caso para Ciências Ambientais.

Parcerias Estratégicas, v. 23, n. 46, p. 135-154, 2019. Disponível em: http://seer.cgee.org. br/index.php/parcerias_estrategicas/article/viewFile/893/811. Acesso em: 01 out. 2020

OLIVEIRA, Eduardo Araujo de et al. Perfil e produção científica dos pesquisadores do CNPq nas áreas de Nefrologia e Urologia. Jornal Brasileiro de Nefrologia, v. 33, n. 1, p. 31- 37, 2011a. Disponível em: https://www.scielo.br/scielo.php?pid=S0101-

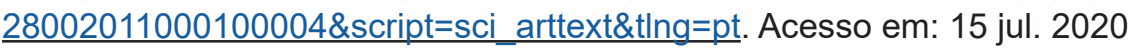

OLIVEIRA, Eduardo Araujo de et al. Pesquisadores do Conselho Nacional de Desenvolvimento Científico e Tecnológico na área de Cardiologia. Arquivos Brasileiros de Cardiologia, v. 97, n. 3, p. 186-193, 2011b. Disponível em: https://www.scielo.br/scielo. php?pid=S0066-782X2011005000086\&script=sci arttext. Acesso em: 15 jul. 2020 
PEDROSO, Bruno et al. Análise da produção técnico-científica dos bolsistas de produtividade do CNPQ da área de educação física no triênio 2010-20121. Pensar a Prática, v. 20, n. 4, p. 719-733, 2017. Disponível em: https://www.revistas.ufg.br/fef/article/ view/42682. Acesso em: 15 jul. 2020

PELLIZZON, Rosely de Fátima; CHIARI, Brasília Maria; GOULART, Bárbara Niegia Garcia de. Perfil dos pesquisadores com bolsa de produtividade em pesquisa do CNPq da área de fonoaudiologia. Revista CEFAC, v. 16, n. 5, p. 1520-1532, 2014. Disponível em: https:// www.scielo.br/scielo.php?pid=S1516-18462014000501520\&script=sci arttext\&tlng=pt. Acesso em: 15 jul. 2020

REGO, Teresa Cristina. Produtivismo, pesquisa e comunicação científica: entre o veneno e o remédio. Educação e Pesquisa, v. 40, n. 2, p. 325-346, 2014. Disponível em: https://www. scielo.br/scielo.php?pid=S1517-97022014000200003\&script=sci arttext\&tlng=pt. Acesso em: 15 jul. 2020

RIGO, Luis Carlos; RIBEIRO, Gabriela Machado; HALLAL, Pedro Curi. Unidade na diversidade: desafios para a Educação Física no século XXI. Revista Brasileira de Atividade Física \& Saúde, v. 16, n. 4, p. 339-345, 2011. Disponível em: https://rbafs.org.br/ RBAFS/article/view/631. Acesso em: 15 jul. 2020

SACCO, Airi Macias et al. Perfil dos bolsistas de produtividade em pesquisa do CNPq atuantes em psicologia no triênio de 2012-2014. Psicologia: Ciência e Profissão, v. 36, n. 2, p. 392-303, 2016. Disponível em: https://www.scielo.br/scielo.php?pid=S141498932016000200292\&script=sci arttext. Acesso em: 15 jul. 2020.

SANTOS, Natacha Carvalho Ferreira; CÂNDIDO, Lucilene Faustina de Oliveira; KUPPENS, Cristiano Lima. Produtividade em pesquisa do CNPq: análise do perfil dos pesquisadores da química. Química Nova, v. 33, n. 2, p. 489-495, 2010. Disponível em: https://www.scielo.brl scielo.php?pid=S0100-40422010000200044\&script=sci arttext. Acesso em: 15 jul. 2020.

SANTOS, Wendel Mombaque dos et al. Perfil dos pesquisadores bolsistas de produtividade em pesquisa na área de enfermagem. Revista de Enfermagem da UFPE, v. 9, n. 2, p. 844-850, 2015. Disponível em: https://periodicos.ufpe.br/revistas/revistaenfermagem/article/ view/10408. Acesso em: 15 jul. 2020.

SCARPELLI, Ana Carolina et al. Academic trajectories of dental researchers receiving CNPq's productivity grants. Brazilian Dental Journal, v. 19, n. 3, p. 252-256, 2008. Disponível em: https://www.scielo.br/scielo.php?pid=S0103-64402008000300014\&script=sci arttext. Acesso em: 15 jul. 2020.

SILVA, Edna Lúcia da; MENEZES, Estera Muszkat; PINHEIRO, Liliane Pinheiro. Avaliação da produtividade científica dos pesquisadores nas áreas de ciências humanas e sociais aplicadas. Informação \& Sociedade: Estudos, v. 13, n. 2, p. 193-222, 2003. Disponível em: https://brapci.inf.br/ repositorio/2010/11/pdf 6f837e4193 0013272.pdf. Acesso em: 15 jul. 2020.

SOUSA SANTOS, João Henrique de; KIND, Luciana. Produtividade acadêmica e modulações no trabalho do pesquisador em Psicologia. Psicologia em Revista, v. 22, n. 1, p. 223-244, 2016. Disponível em: http://periodicos.pucminas.br/index.php/ psicologiaemrevista/article/view/P.1678-9523.2016V22N1P223. Acesso em: 15 jul. 2020.

SPILKI, Fernando Rosado. Perfil dos bolsistas de produtividade do Conselho Nacional de Desenvolvimento Científico e Tecnológico (CNPq) na área de Medicina Veterinária. Pesquisa Veterinária Brasileira, n. 33, v. 2, p. 205-213, 2013. Disponível em: https://www. scielo.br/scielo.php?pid=S0100-736X2013000200012\&script=sci arttext\&tlng=pt. Acesso em: 15 jul. 2020. 
TANI, Go. Cinesiologia, educação física e esporte: ordem emanente do caos na estrutura acadêmica. Motus Corporis, v. 3, n. 2, p. 9-50, 1996.

TANI, Go. Os desafios da pós-graduação em educação física. Revista Brasileira de Ciências do Esporte, v. 22, n. 1, p. 79-90, 2000. Disponível em: http://revista.cbce.org.br/ index.php/RBCE/article/view/755. Acesso em: 15 jul. 2020.

TANI, Go. Editoração de periódicos em educação física/ciências do esporte: dificuldades e desafios. Revista Brasileira de Ciências do Esporte, v. 36, n. 4, p. 714-721, 2014. Disponível em: https://www.sciencedirect.com/science/article/pii/S0101328914000043. Acesso em: 15 jul. 2020.

TANI, Go. Educação física: por uma política de publicação visando à qualidade dos periódicos. Revista Brasileira de Ciências do Esporte, v. 29, n. 1, p. 9-22, 2007. Disponível em: http://revista.cbce.org.br/index.php/RBCE/article/view/6. Acesso em: 15 jul. 2020.

TANI, Go. Pós-graduação em educação física: crescimento e correção da rota. In: MOREIRA, Wagner Wey; NISTA-PICCOLO, Vilma Lení. Educação física e esporte no século XXI. Campinas: Papirus, 2016. p. 153-171.

TANI, Go; CORRÊA, Umberto César. Ciência e comunicação científica na educação física/ ciências do esporte. In: CARNEIRO, Felipe Ferreira Barros; FERREIRA NETO, Amarílio; SANTOS, Wagner dos. Comunicação científica em periódicos. Curitiba: Appris, 2019. p. 237-259.

VITOR-COSTA, Marcelo; MAIA DA SILVA, Priscila; SORIANO, Jeane Barcelos. A avaliação da produtividade em pesquisa na Educação Física: reflexões sobre algumas limitações dos indicadores bibliométricos. Revista Brasileira de Educação Física e Esporte, v. 26, n. 4, p. 581-597, 2012. Disponível em: https://www.scielo.br/scielo.php?pid=S180755092012000400005\&script=sci_abstract\&tlng=es. Acesso em: 15 jul. 2020.

WEBER, João Luís Almeida et al. Perfil dos pesquisadores bolsistas de produtividade científica em Psicologia do Conselho Nacional de Desenvolvimento Científico e Tecnológico. Estudos de Psicologia, v. 32, n. 1, p. 1-11, 2015. Disponível em: https://www.scielo.br/ scielo.php?pid=S0103-166X2015000100001\&script=sci arttext\&tlng=pt. Acesso em: 15 jul. 2020. 
Abstract: This study analyzes the scientific production by Physical Education (PQEF) PhD student researchers holding productivity grants from Brazil's National Council of Technological and Scientific Development (CNPq), in order to understand their trajectory and look into publication trends and possible changes in their characteristics in 1991-2016. The curricula of the $91 \mathrm{PQ}-\mathrm{EF}$ researchers holding grants in 2017 were analyzed in terms of articles published in journals, number of co-authors, and authors' positions in the articles, as well as how these factors relate according to productivity grant levels and time taken for completing their $\mathrm{PhD}$ studies. The results revealed a significant increase in per capita scientific production and also an increase in multi-author publications as well as the number of co-authors, suggesting publication strategies aimed at higher productivity.

Keywords: Physical Education. Grants. Education, graduate. Scientific production indicators.

Resumen: Este estudio se propuso analizar la producción científica de los becarios de productividad del Consejo Nacional para el Desarrollo Científico y Tecnológico (CNPq) en el área de Educación Física (PQ-EF), tratando de comprender su trayectoria y verificar las tendencias con respecto a la publicación de artículos y los posibles cambios en sus características en el período de 1991 a 2016 . Se analizaron los currículos de los 91 becarios PQ-EF en curso en 2017, en lo que se refiere a los artículos publicados en revistas, el número de coautores y la ubicación en la autoría de los artículos, así como la relación entre estos factores según los niveles de beca y el tiempo de finalización del doctorado. Los resultados revelaron un aumento significativo en la producción científica per cápita y también un aumento en las publicaciones de varios autores, con un número creciente de coautores, lo que sugiere estrategias de publicación destinadas a aumentar la productividad.

Palabras clave: Educación Física. Becas. Educación de Posgrado. Indicadores de producción científica. 


\section{LICENÇA DE USO}

Este é um artigo publicado em acesso aberto (Open Access) sob a licença Creative Commons Atribuição 4.0 Internacional (CC BY 4.0), que permite uso, distribuição e reprodução em qualquer meio, desde que o trabalho original seja corretamente citado. Mais informações em: http://creativecommons.org/licenses/by/4.0

\section{CONFLITO DE INTERESSES}

Os autores declararam que não há conflito de interesses neste trabalho.

\section{CONTRIBUIÇÕES AUTORAIS}

Go Tani: Concepção do estudo. Análise e interpretação dos dados. Redação do artigo.

Ricardo Drews: Coleta de dados. Análise e interpretação dos dados. Redação do artigo.

Umberto Cesar Corrêa: Concepção do estudo. Análise e interpretação dos dados. Redação do artigo.

\section{FINANCIAMENTO}

O presente trabalho foi realizado sem qualquer apoio financeiro.

\section{COMO REFERENCIAR}

TANI, Go; DREWS, Ricardo; CORRÊA, Umberto Cesar. Tendências da produção científica dos bolsistas de produtividade em pesquisa do CNPq da área de Educação Física. Movimento (Porto Alegre), v.26, p. e26088, jan./dez. 2020. Disponível em: https://seer.ufrgs.br/Movimento/article/view/105434. Acesso em: [dia] [mês abreviado]. [ano]. DOI: https://doi.org/10.22456/1982-8918.105434

\section{RESPONSABILIBADE EDITORIAL}

Alex Branco Fraga*, Elisandro Schultz Wittizorecki*, Ivone Job*, Mauro Myskiw*, Raquel da Silveira*

*Universidade Federal do Rio Grande do Sul, Escola de Educação Física, Fisioterapia e Dança, Porto Alegre, RS, Brasil 